\title{
Project Surveys for Determining and Defining Key Performance Indicators in the Development of Smart Grids in Energy Systems
}

\author{
Mehmet Rida Tur*t, Ramazan Bayindir** \\ *Department of Electrical and Energy, Batman University, Batman, Turkey \\ ** Department of Electrical and Electronics Engineering, Gazi University, Ankara, Turkey
}

(mrida.tur@batman.edu.tr, bayindir@gazi.edu.tr)

$\ddagger$

Batman University Center Campus 72060, Batman, Turkey, Tel: +90 535744 9474, Fax: +90 488217 3601, mrida.tur@batman.edu.tr

Received: 01.06.2019 Accepted:22.06.2019

\begin{abstract}
With the increasing energy demand, technology and computer technology, with the development of technology, it has become compulsory to use in electricity networks. Many smart grid projects have been implemented, including the establishment of advanced measuring infrastructure, smart meter installation, electricity generation from renewable energy sources, energy efficiency, use of electric vehicles and smart buildings. Many developed and developing countries have created platforms for developing Smart Grids and have set up a roadmap for smart grids. In particular, the main purpose of the European Union; By 2020, it was possible to integrate renewable energy sources by $20 \%$, increase energy efficiency by $20 \%$ and reduce carbon emissions by $20 \%$. The US government finances several smart grid projects in its country with a certain amount of repayment. Japan launched smart city pilot applications by taking smart grid projects one step further. This study has enabled us to explore projects that have taken place and planned around the world. Europe, the US, Japan, China, South Korea, Canada and Australia has become interested in smart grids. In this study, development and project examples of smart grids worldwide have been investigated.
\end{abstract}

Keywords Smart grid applications; modern network projects; demand side management; smart meter; new network technologies.

\section{Introduction}

Along with the developing technology, changes in the energy sector have been inevitable as in all other fields. In this direction, the transition from the classical network to the smart grid has been the focus of both developing and developing countries, which has made many projects and investments in the field. This study basically makes a worldwide analysis of these projects. The use of renewable energy sources, which are increasing day by day, on the one hand, reduces the $\mathrm{CO} 2$ emissions released to the nature, while increasing the research on supply security. In addition to these positive contributions to the power system, renewable energy sources cause some additional uncertainties and unpredictable events in the transmission and distribution networks. The impossibility of storing large amounts of electricity supplied to consumers at an economical price makes the system operators more difficult to balance production supply with real-time customers' demands. Distributed generation power systems; It provides shorter losses in transmission, distribution and conversion losses as it has shorter lines than conventional network. However, these systems require highly complex solutions for effective operation, management and control.

The rapid increase in electricity demand in recent years has caused some difficulties in terms of both energy producers and system operators. In addition, these problems are expected to increase in the future only due to the electrification of the transport sector and the increase in building heating systems. The need to meet the increasing demand for high energy creates an additional burden on traditional power plants. Practically, the power system infrastructure cannot fully meet the needs and increased complexity caused by new scenarios in the electrical system. Therefore, providing a bi-directional energy and information flow to create an automated and distributed energy distribution network is a major requirement for today's modern electrical systems. In this concept, IT and Communication Technologies are the basic elements for realtime data collection and processing. 
All these relevant issues form the basis of the smart grid concept. In the second part of this study, the main developing actors in the smart network are examined and in the third part, the strategies and applications for smart network are advocated. In the fourth chapter, new technologies in the field of smart energy are evaluated.

\section{Identifying and Defining Basic Indicators in Developing Smart Grids}

Smart grids represent the development of traditional electric grids, where new actors and scenarios are combined, as shown in Figure 1, to provide a safer, sustainable and costeffective and at the same time high supply security and quality electricity supply. Many countries around the world are taking measures to change and improve the current electricity grid model. Smart grid investments in the US, which is one of the countries that care about the smart grid model, amounted to approximately $\$ 197$ billion in 2015 [1]. Western Europe plans to invest $\$ 133.7$ billion into smart grid infrastructure by 2027. A Washington-based firm predicts that Germany's investment in smart grid infrastructure will reach $\$ 23.6$ billion in 2017-2026 [2]. In addition to these countries, India, China, Korea, Brazil, Australia and other countries are trying to develop their existing networks according to technological requirements with various projects such as countries that invest in smart grid.

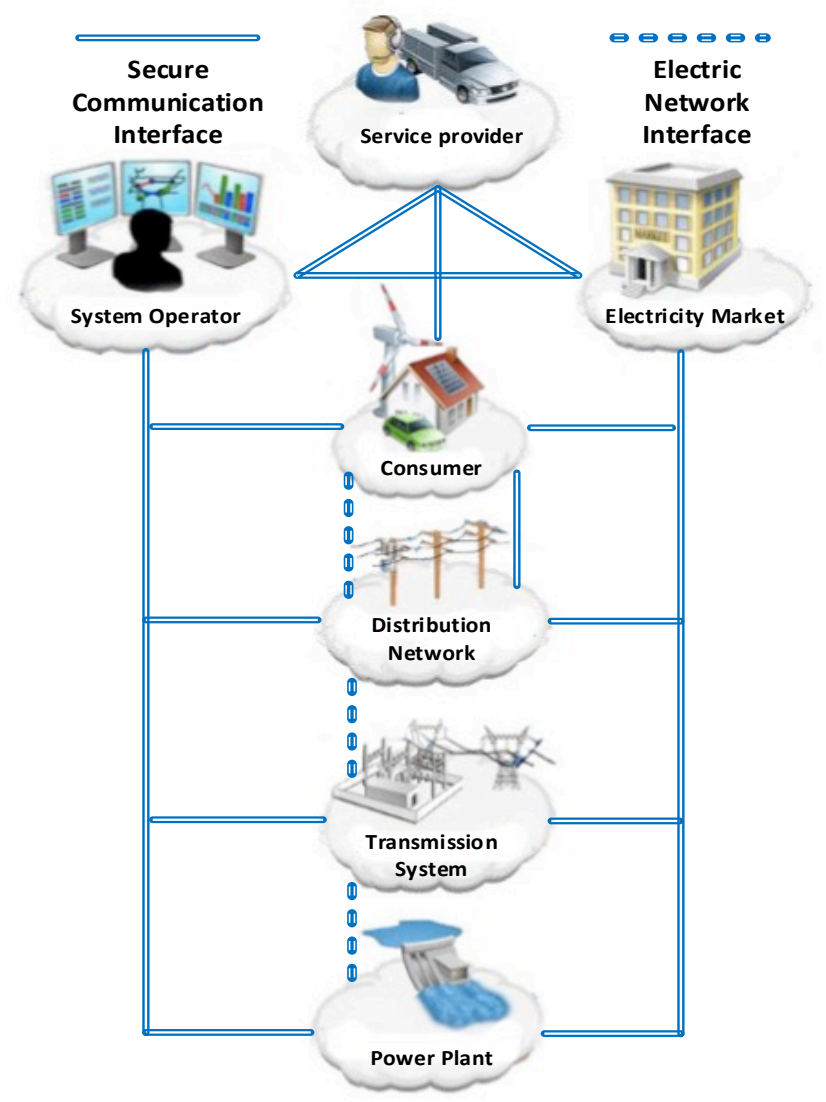

Fig. 1. Energy, communication and data flow in smart grids.

Most of these projects are basically research and development projects. The map shown in Figure 2 shows the distribution of smart grid projects in Europe. The road map for most of the world countries on network modernization consists of projects that have been prepared by smart network focus [3]. Turkey cannot perform adequately in terms of smart grid activities. Therefore, socio-economic and political issues need to be developed in the context of dynamic growth at the global level. Recently, many studies have been carried out on the transformation of classical networks into smart ones around the world. Some studies have analyzed the elements that affect the choice of the best governance policy or energy strategy. Others focus on the optimized integration of a technology volume in a network [4-9].

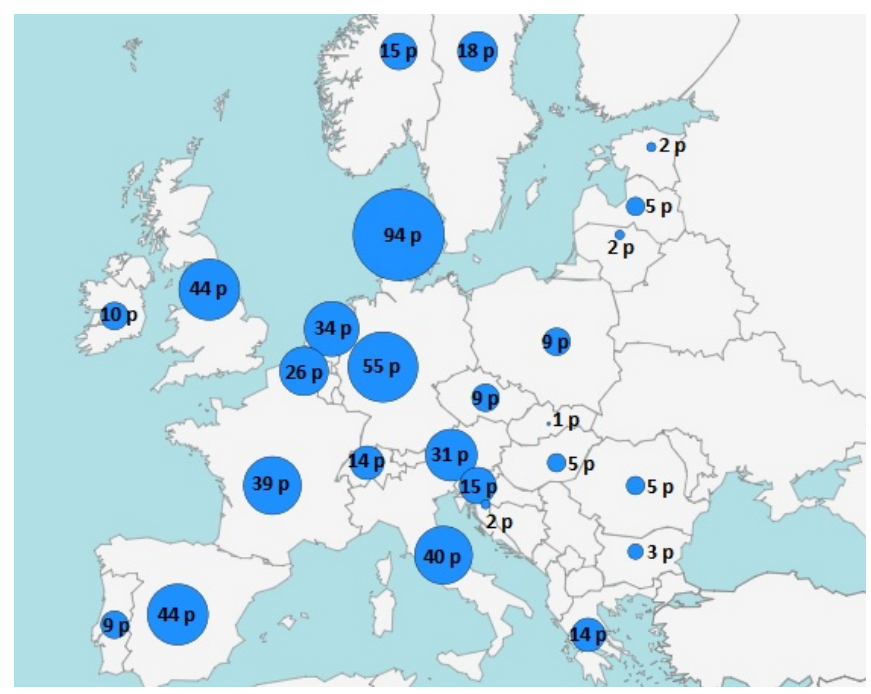

Fig. 2. Number of smart grid research projects by country (' $p$ ' is for the number of projects).

The transition from a conventional network to an intelligent state, in most cases, demands the highly accurate use of multi-parameter decision-making software [10] to take into account all the different parameters involved in a decision [11]. Other studies focus on the special case studies of networks in the world. Apart from the islands [12], many other studies have been conducted [13-16] showing an intelligent network that uses substantially wind power to optimize smart island networks. For an effective management of the energy system needed in energy systems, it is necessary to offer more modern solutions by using innovations in the sector and to make sufficient investment in technological requirements $[17,18]$.

The statistics obtained show the estimated market investment value of the global smart grid infrastructure development market in 2017 with 2023 forecasting. It is expected that the size of the smart grid market will increase from 23.8 billion US dollars in 2018 to USD 61.3 billion in 2023 by 2023 and increase by $20.9 \%$ Compound Annual Growth Rate in the forecast period. Government policies and legal requirements, awareness of carbon footprints, modernization of aging grid infrastructure, and improved network reliability and effective downtime response enable the adoption of smart grid solutions. The worldwide market development of modern networks from 2017 to 2023 by region is shown in Figure 3 (billion USD) [19]. 


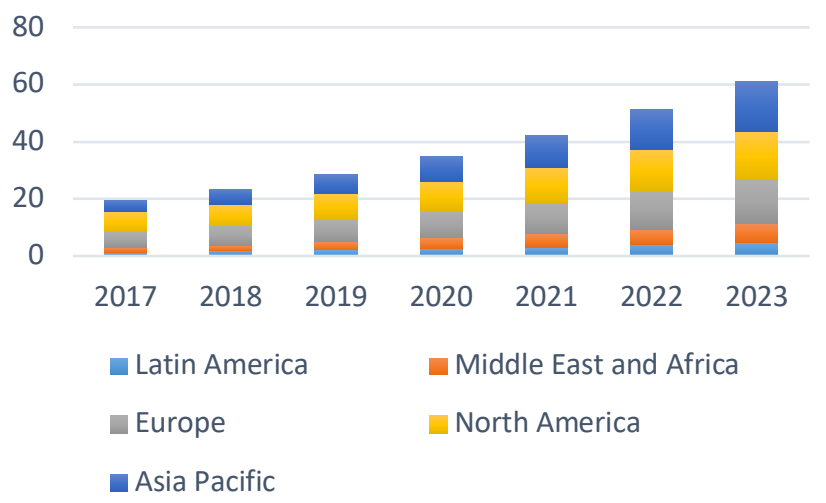

Fig. 3. Worldwide market value for Smart grids between 2017-2023

It is expected to have the highest market share in terms of smart grid distribution management, production and consumption. Smart grid deployment management is effective in many ways, which are software platform that integrates distribution and energy management system, audit control and data collection, distributed energy resources and demand response management for real-time power distribution management and optimization.

\section{Research \& Development studies for Smart Grid Strategies and Applications}

Private investment still represents the largest share of resources for both Research \& Development (R \& D) and promotional projects, even if international financing is of the utmost importance. The relative importance of this situation is particularly important for demonstration projects where private investment represents about $60 \%$ of the allocated resources. On the other hand, as shown in Figure 4, this share is about $40 \%$ for $\mathrm{R} \& \mathrm{D}$ projects [20].

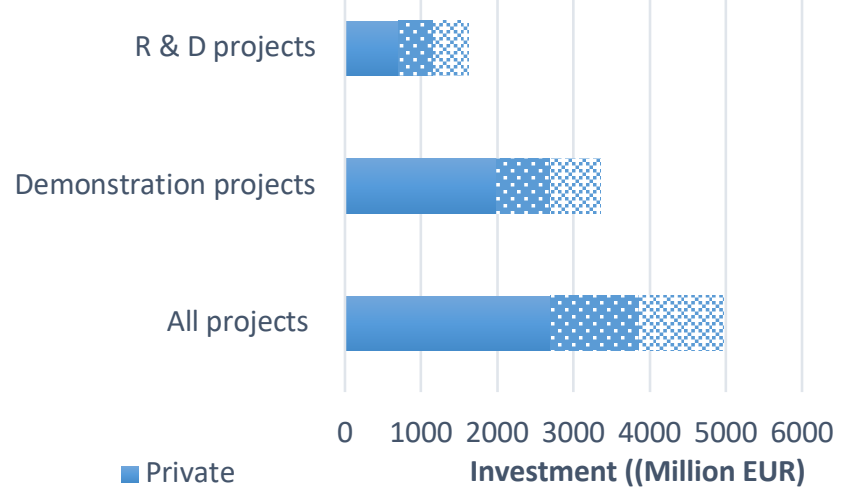

Fig. 4. $R$ \& D projects investment rates.

The number of completed projects on investments in smart grid projects in Europe, the amount of budget used for these projects and the amount of investment per capita are given in Table 1. These smart grid development laboratory activities should focus not only on one technology, but on the integration and common features of systems and interoperability between components.
Table 1. Information on investments in smart grid projects in Europe [21].

\begin{tabular}{lccc}
\hline \multicolumn{1}{c}{ Country } & $\begin{array}{c}\text { Number of } \\
\text { Projects }\end{array}$ & $\begin{array}{c}\text { Project Budget } \\
\text { (million } € \text { ) }\end{array}$ & $\begin{array}{c}\text { Investment } \\
\text { per capita } \\
(€)\end{array}$ \\
\hline Denmark & 94 & 47 & 33.08 \\
Germany & 55 & 216.8 & 2.65 \\
Britain & 44 & 275.1 & 4.37 \\
Spain & 44 & 176.1 & 3.81 \\
Italy & 40 & 188.8 & 3.1 \\
France & 39 & 215.1 & 3.39 \\
Netherlands & 34 & 91.7 & 5.48 \\
Australia & 31 & 51.6 & 6.12 \\
Belgium & 26 & 78.4 & 7.1 \\
Swedish & 18 & 77.8 & 8.21 \\
Norway & 15 & 14.1 & 2.81 \\
Slovenia & 15 & 23.4 & 11.78 \\
Switzerland & 14 & 16.3 & 2.05 \\
Greece & 14 & 41.5 & 3.68 \\
Finland & 13 & 184.6 & 8.7 \\
Ireland & 10 & 9 & 1.95 \\
Portugal & 9 & 41.8 & 3.97 \\
Poland & 9 & 4.4 & 0.11 \\
Czech Republic & 9 & 32.4 & 3.08 \\
Latvia & 5 & 2.8 & 1.39 \\
Hungary & 5 & 11.2 & 1.12 \\
Romania & 5 & 2.4 & 0.11 \\
Bulgaria & 3 & 2.4 & 0.33 \\
Estonia & 2 & 0,4 & 0,3 \\
Lithuanian & 2 & 5,9 & 1,96 \\
Croatia & 2 & 0,6 & 0,15 \\
Slovakia & 1 & 6 & 1,11 \\
Cyprus & 1 & 1,3 & 1,55 \\
\hline & & & \\
\hline
\end{tabular}

The main objective of these projects is to evaluate the new technologies for smart grids and to determine the most suitable technological solutions, and to make smart grid modeling, applications and tests to be prepared for our national power system. There are about 100 smart grid laboratories in Europe and America with similar structure [22].

Figure 5 (a) and (b) shows number of the distribution of the laboratories in question. In this context, project-based infrastructure developments have been significantly increased and the transition to the smart grid model is accelerated.

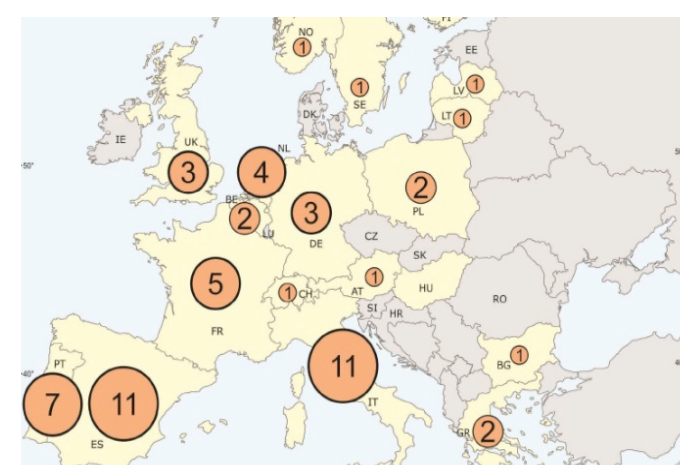

(a) 


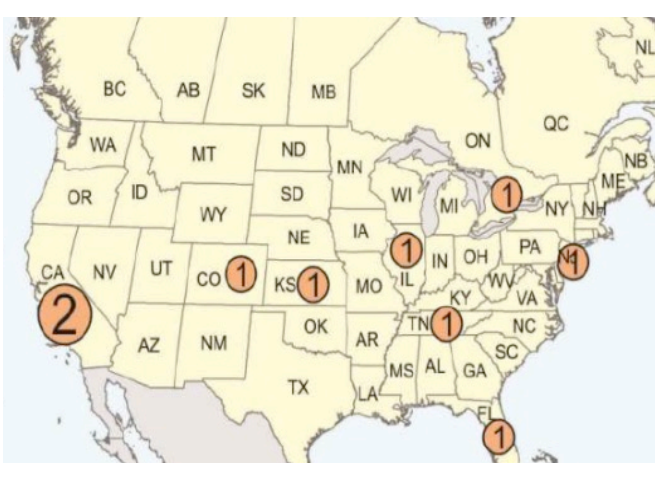

(b)

Fig. 4. Distribution of smart grid laboratories a) Europe and b) America

\section{Smart Grid Components and New Technology Requirements; Smart Meter Application}

Smart meters, the most important and common component used in smart grids, have proven to be a blessing to consumers who have the freedom to monitor and regulate their power usage. These counters bring great advantages in auditing by providing uninterrupted bidirectional communication between consumers and their related services, with utilities that help consumers to be detected in a timely manner with regard to power outages and to ensure service reliability. Investments in new and intelligent technologies in the energy market are in a roll, as long as all types of public service providers continue to move towards a data-based paradigm. The digitalization trend in the field of power and usage and the sales of smart meters will be the result of a large increase in 2018 and a healthy jump in 2019 and later.

Intelligent meters empower customers to take advantage of new technologies, including solar PV, smart home technologies and battery storage, as well as customer-side control. Energy efficiency, savings and invoice transparency will be the focus of customers used by the manufacturer to generate profitable profits. In 2018, the smart meter sector in the global market was around $\$ 10$ billion. It is estimated that this market reflects growth in a CAGR (Compound annual growth rate) of more than $8 \%$ from 2018 to 2026 . These meters, which are an important component of the network infrastructure, are the cornerstone of our smart energy system, which will accelerate the installation of smart meters, which are supported by software and hardware developments, which remove the ability to install in more areas this year with energy suppliers. Equally important, the pre-installed smart meters are set up for an upgrade to ensure that all devices are interoperable with the Data Communications Company network, which is a process that will allow all devices to be adopted, saved, and temporarily regaining the full capacity of lost timers. These developments are fundamentally important on two fronts:

- $\quad$ First, energy suppliers and network operators will have a large amount of consumption data, as an increasing number of people can take advantage of the energy-saving advantages of smart meters, and second, there are millions of meters that are expected to join the network.

- This will be used to improve energy services to consumers on the one hand - for example, to improve smart timetable tariffs and to extend a halfhour settlement to local customers. On the other hand, operators will be able to use these extra data to obtain a more precise picture of supply and demand, which will enable them to integrate intermittent renewable energy sources more effectively into the network.

\section{Conclusion}

The benefits of the Smart Grid have a dynamic structure because they are updated by following the technological, economic and social changes together. The main problem facing projects developed for smart grid systems is integration. For this reason, it is necessary to design, develop and test smart grid usage cases and technologies to examine Smart Grids, and access to both real power systems and laboratory power systems is required to achieve this. Future power systems with cyber-physical elements are expected to be highly complex. In terms of our national power system, the design, development, implementation and verification of smart grid-based projects will play an important role in building the infrastructure for future research and technology studies. It is necessary to focus on information, communication and automation / control as well as an integrated approach to analyze and evaluate intelligent grid configurations addressing the power system. Such infrastructure also supports system analysis, evaluation and testing. In summary, the following points are expressed in supportive steps in smart grid research:

- Implement a cyber-physical (multi-domain) approach to analyze and validate system-level smart networks,

- Inverter based RES will provide the methods of analyzing intelligent network components (power system, ICT (Information and Communication Technologies), automation / control) such as storage systems, intelligent transformer centers, measurement systems, communication network, control room, voltage / frequency control, intelligent protection,

- Design, research and development, verification and testing methods (including the combination of both methods) will be realized in the simulation (based on the real world) and in the laboratory (real-world) for smart grids and related components,

- Smart grid systems, RES, electric vehicles or ICT can work on a large number of research areas. This system will also enable a wide range of actors from energy providers to communication operators, equipment manufacturers, standardization organizations, automobile industry, production and consumption consumers, 
- $\quad \mathrm{R} \& \mathrm{D}$ in the field of modelling, validation and testing of a wide range of smart network usage will allow.

\section{References}

[1] https://cleantechnica.com/2017/06/23/western-europesmart-grid-investment-reach-133-7-billion-next-10years-northeast-group-reports/2017/06/23 [last accessed on 2017/06/23]

[2] https://www.metering.com/news/germany-23-6bnsmart-grid-2026/ [last accessed on 2017/01/2]

[3] https://www.gov.uk/government/uploads/system/uplo ads/attachment data/file/285417/Smart_Grid_Vision and RoutemapFINAL.pdf [last accessed on 2018/07/12]

[4] J. Hamilton, M. Negnevitsky, X. Wang, A. Tavakoli, M. Mueller-Stoffels, "Utilization and Optimization of Diesel Generation for Maximum Renewable Energy Integration. In Smart Energy Grid Design for Island", Countries; Springer: Cham, Switzerland, 2017; pp. 21-70.

[5] V. Karthikeyan, S. Rajasekar, V. Das, P. Karuppanan, A.K. Singh, "Grid-Connected and Off-Grid Solar Photovoltaic System. In Smart Energy Grid Design for Island Countries", Springer: Cham, Switzerland, 2017; pp. 125-157.

[6] A. Awasthi, V. Karthikeyan, V. Das, S. Rajasekar, A.K. Singh, "Energy Storage Systems in Solar-Wind Hybrid Renewable Systems. In Smart Energy Grid Design for Island Countries; Springer: Cham, Switzerland, 2017; pp. 189-222.

[7] D. Aitchison, M. Cirrincione, G. Cirrincione, A. Mohammadi,"Pucci, M. Feasibility Study and Design of aFlywheel Energy System in a Microgrid for Small Village in Pacific Island State Countries. In Smart Energy Grid Design for Island Countries" Springer, 2017; pp. 159-187.

[8] A: Urtasun, P. Sanchis, L. Marroyo, "Energy Management of AC-Isolated Microgrids Based on Dist. Storage Sys. and Ren. Energy Sources", Springer: Cham, Switzerland, 2017; pp. 327-379.

[9] G. Vitale, "Frequency Stability Improvement in Weak Grids by Storage Systems". In Smart Energy Grid Design for Island Countries; Springer: Cham, Switzerland, 2017; pp. 223-258

[10] T. Madiba, R. Bansal, J. Justo and K. Kusakana, "Optimal Control System of Under Frequency Load Shedding in Microgrid System with Renewable Energy Resources". In Smart Energy Grid Design for
Island Countries; Springer: Cham, Switzerland, 2017; pp. 71-96.

[11] E. Ghiani, et. al. "Multidisciplinary Approach for the Development of Smart Distribution Networks". Energies 2018, 11, 2530.

[12] Abedalsalam B. A. et al., "Foundational Support Systems of the Smart Grid: State of the Art and Future Trends" International Journal of Smart Grid, ijSmartGrid, Vol. 2, No. 1, March, 2018,

[13] Cross, S. et. al. "Benchmarking island power systems: Results, challenges, and solutions for long term sustainability". Renew. Sustain. Energy Rev. 2017, 80, 1269-1291.

[14] D., Aitchison; et. al. "Feasibility Study and Design of a Flywheel Energy System in a Microgrid for Small Village in Pacific Island State Countries". In Smart Energy Grid Design for Island Countries; Springer: Cham, Switzerland, 2017; pp. 159-187.

[15] S.S. Chand, A. Iqbal, M. Cirrincione, F. Islam, K. Mamun, A. Kumar, "Identifying Energy Trends in Fiji Islands". In Smart Energy Grid Design for Island Countries; Springer 2017; pp. 259-287.

[16] D. Majumder, J. Tazdik, K.A. Uddin, M.A. Al Matin, "KPI for Solar PV-diesel hybrid mini grids in remote islands of Bangladesh". Energy Procedia 2016, 103, 262-267.

[17] P. Dionysios, "A Methodology for Determination and Definition of Key Performance Indicators for Smart Grids Development in Island Energy Systems" Energies 2019, 12, 242; doi:10.3390/en12020242.

[18] M. R. Tur, R. Bayindir, "The Requirements of The Technique of Communication from Machine to Machine Applied in Smart Grids", SRM 2019.

[19] G. Marlene, P. Vice, B. Company, "Statista - The Statistics Portal Statista GmbH Johannes" BrahmsPlatz 120355 Hamburg Germany 2017.

[20] F., Gangale, at. Al. "Smart grid projects outlook 2017", Facts, figures and trends in Europe, doi:10.2760/701587.

[21] http://ses.jrc.ec.europa.eu/smart-grid-projects-europe [last accessed on 2018/01/12]

[22] N. Andreadou, M. Olariaga Guardiola, I. Papaioannou, G. Prettico, "Smart Grid Laboratories Inventory”, EUR 28319 EN, doi:10.2790/099953. 